\title{
The management of patients with stable coronary syndromes
}

Authors: Patrick Commerford MBchB, FCP (SA), FACC

Corresponding author

Professor PJ Commerford

Cardiac Clinic, Department of Medicine

University of Cape Town and Groote Schuur Hospital

Anzio Road, Observatory

Cape Town, 7925

Email: picomfrd@uctgsh 1.uct.ac.za

ABSTRACT In coronary artery disease, symptoms and prognosis are not closely linked and sudden unexpected death or devastating acute myocardial infarction may be the first manifestation. In treating patients with stable coronary disease, we wish to both relieve symptoms and prevent adverse outcomes. Percutaneous revascularization provides excellent symptom relief but has no positive prognostic benefit in patients with stable coronary disease. The lesion causing the angina, treated by a stent, is not necessarily the lesion determining prognosis. Simple lifestyle modification and drug therapy are important determinants of prognosis. Coronary bypass graft surgery improves prognosis in well-defined subsets of patients and the application of percutaneous interventions in patients who might be better served by surgery can be questioned. It can be argued that the emphasis placed on percutaneous intervention in patients with stable disease may have adverse consequences.

Some may justifiably argue that the management of patients with stable coronary disease is hardly a relevant topic at a national meeting of specialist cardiologists. Given the ubiquity of the condition, all health care professionals should be fully-informed and expert in its management. The guidelines issued by a number of professional organizations around the world are clear and explicit and hardly require specialist training for implementation. Many are issued in extremely simple formats readily understandable by nonmedically trained persons. Indeed, much of the essential information about the life-style choices that may prevent the development of the condition or avert its devastating consequences is readily available in broadcast media, daily newspapers and popular magazines.

This brief and admittedly incomplete review addresses only some issues of interest and importance. There is some new information about the importance of risk factors and life-style choices that deserves emphasis. When considering medical treatment, appropriate use of established therapies is important and it is becoming clear that avoidance of some commonly used medications may be important for patients with coronary disease. Revascularization strategies are central to much current discussion and debate on how best to manage patients with the acute coronary syndromes. There is still controversy on how or when it is best to advise revascularization for patients with stable symptoms.

The Framingham data suggest that stable angina may be the presenting symptom in about $40 \%$ of all patients with coronary disease. ${ }^{(1)}$ It is the management of those patients that is the focus of this discussion. Large clinical trials and meta-analyses of the results have resulted in the development of a considerable body of evidence that is available to clinicians and patients to guide risk stratification and therapeutic choices in the acute coronary syndromes. There is much less good information available to guide our choices in patients with stable coronary syndromes.

\section{SYMPTOMS AND PROGNOSIS IN CORONARY DISEASE}

In some diseases, symptoms and prognosis are closely linked. Patients who feel sick die and those who feel well do not. In coronary disease. there is an unfortunate disconnect between symptoms and prognosis. The Framingham data is congruent with everyday experience. Sudden unexpected death or devastating acute myocardial infarction with significant residual disability may be the first manifestation of the disease. Conversely patients with chronic stable angina, managed appropriately, may have a good prognosis and excellent quality of life.

Patients with stable angina are rightly concerned that the coronary stenosis causing their symptoms may progress to cause myocardial infarction or death and will welcome any intervention to remove the stenosis in the mistaken belief that the intervention relieving symptoms will also improve prognosis. We now know that this is not correct and this knowledge should influence our practice and the information we give our patients.

There are several contemporary reports of a surprisingly good prognosis in patients with established coronary disease and stable symptoms when managed medically. The annual incidence of death is between I-2\% and the incidence of myocardial infarction is similar. (2,3) Treated appropriately, stable angina is a condition with a reasonable prognosis in the majority of middle-aged or older patients in which it occurs. The challenge is to ensure that our treatments optimize survival and do not impact adversely on it. Recent trials of revascularization compared to medical treatment in stable angina confirm the relatively benign prognosis of patients treated medically. In some the prognosis on medical treatment was better than in those treated by percutaneous revascularization. ${ }^{(4)}$ In my view, there is insufficient published evidence to support the performance of percutaneous intervention (PCl) in patients with chronic stable angina for any reason other than relief of symptoms of angina. The views of some practitioners 
and patients that $\mathrm{PCl}$ improves prognosis or averts future adverse events are not supported by the available evidence. When the risks of the disease are low and any intervention carries a small but definite risk of harm, the choice of therapy to influence prognosis positively becomes difficult. The issue remains unsettled and the results of the COURAGE trial, which compares intensive medical therapy to a strategy of $\mathrm{PCl}$ plus intensive medical therapy, are eagerly awaited. ${ }^{5}$

\section{IS RISK FACTOR MODIFICATION USEFUL?}

The value of risk factor modification and the magnitude of its impact on prognosis sometimes is lost in the argument as to whether or how best patients should be revascularized. Although never formally tested against revascularization, the magnitude of prognostic benefit of effective risk factor intervention arguably exceeds many of our medical interventions.

The INTERHEART study confirmed that smoking was an extremely important risk factor for myocardial infarction in Africa, showed that all forms of tobacco use were harmful, that there was a clear dose-effect relationship and that second-hand smoke was harmful. ${ }^{(6)}$

There is now overwhelming evidence of the harmful effects of secondhand smoke . ${ }^{(7,8)}$ Smoking cessation and avoidance may be the single most powerful intervention we can offer in terms of improving prognosis. How much time and effort do we devote to this, compared to the time spent in the catheterization laboratory?

Exercise training improves symptoms in patients with coronary disease. Training shifts the heart rate / oxygen consumption curve to the right. Work elicits a slower heart rate response and the onset of angina is delayed. ${ }^{(9)}$ There is admittedly limited, but nonetheless intriguing, information suggesting that exercise may offer greater prognostic benefit than $\mathrm{PCl}$ in stable patients. In a small trial which randomized stable male patients with coronary lesions eligible for $\mathrm{PCl}$ to intervention or an exercise program combined with regular counseling, event-free survival was better in those treated conservatively. ${ }^{(10)}$

Advice and encouragement to modify lifestyle seem all too often to be an afterthought and are considered by both practitioners and patients as of lesser importance than the apparently potent scientific and technological interventions of drugs and devices. The reality is sobering. Whereas PCl has no proven positive impact on prognosis in stable coronary disease, lifestyle changes may have an effect at least as great as and possibly greater than many of the commonly prescribed pharmacological interventions that are of proven benefit. (II)

\section{PHARMACOLOGICALTHERAPY}

This is not intended to be a comprehensive review of drug therapy, but rather a discussion of some aspects, particularly as they may influence prognosis.

Aspirin is well established and widely and appropriately used in most patients with coronary disease. The prognostic benefits are greatest in patients at highest risk (those who have recently suffered an acute coronary syndrome) and may be much less in stable patients in whom the bleeding risk may closely approximate the benefit in terms of vascular events avoided. (12) Bleeding risk is related to dose and low-dose aspirin is not generally available in the state sector in South Africa, with the consequence that the standard prescription is $150 \mathrm{mg}$, which is double the lowest effective daily dose. ${ }^{2}$ This may be particularly harmful in Africa where Helicobacter pylori positivity is more common than in Europe and North America.

The benefit of secondary prevention with statins is clearly established. The inordinate delay in making them available for treatment and restrictions on dose-levels in some regions of the state sector (the Western Cape) may have been driven by cost. Despite recent reductions in price, patients in private practice often find it difficult to maintain treatment for prolonged periods of time.

However, any reduction in LDL-cholesterol is better than none ${ }^{(13)}$ and even the very low doses available in some public-sector hospitals do have a beneficial effect and patients should be encouraged to persevere.

The long-term protective effect of the angiotensin converting enzyme inhibitors (ACE-Is) in stable patients are well-established. (14,15) Generic agents are now readily available, but are surprisingly infrequently used in patients with angina who meet the criteria as defined in the trials which showed prognostic benefit. The reasons for this underutilization are unclear. At least partly it may be due to aggressive marketing of the angiotensin receptor blockers, which as yet lack evidence for similar protective benefit.

Beta-blockers offer very effective relief of symptoms and have been considered to offer prognostic benefit compared to calcium channel blockers in uncomplicated patients with stable angina, but there is no good evidence supporting this opinion. ${ }^{(16)}$ They clearly do offer prognostic benefit in heart failure and after myocardial infarction and, therefore, should be part of the therapy of all such patients unless contraindicated.

In addition to utilizing agents that improve prognosis, it is essential to avoid those that may cause harm. The increased vascular risk associated with the use of selective cyclooxygenase-2 inhibitors is well established and has resulted in the withdrawal of some of these agents. Whether similar risk attaches to the use of nonselective nonsteroidal anti-inflammatory drugs (NSAIDs) is unclear, but worrying, given their widespread and indiscriminate use. They are freely available over the counter, used for a variety of non-specific aches and pains and are often prescribed at the patients request without a good indication. A recent report that NSAIDs in high dose increase mortality in patients with previous myocardial infarction is concerning. (17) The number needed to treat to cause harm is disturbingly low and it seems prudent to advise caution in prescribing these agents to patients with vascular disease and to ensure that they are only used for valid indications. It is sobering to consider that in some state sector facilities it is easier to prescribe NSAIDs (which may cause harm) than statins (which definitely result in benefit) for patients with angina.

\section{REVASCULARIZATION IN STABLE ANGINA:WHEN AND HOW?}

All revascularization strategies provide superior symptomatic relief when compared to medical therapy. Any controversy that exists relates to 
prognosis in patients with mild or controlled symptoms. Doctors and patients seem to believe that $\mathrm{PCl}$ and stents, in particular, offer prognostic benefit. The majority of patients referred to my clinic report that they have been told they can have a "little spring" put in "from outside" and that this will protect against future heart attack, death, disability and the need for coronary bypass surgery! The reality for patients with stable angina is somewhat different.

Coronary artery bypass graft surgery (CABG) was shown to offer prognostic benefit when compared to medical therapy in a series of trials. ${ }^{(8)}$ Mortality benefit was proportional to baseline risk and, though small, was definitely present. In contrast, a meta-analysis of trials comparing $\mathrm{PCl}$ to medical therapy in nonacute coronary artery disease failed to show any benefit in terms of death, myocardial infarction, or the need for subsequent revascularization. ${ }^{(19)}$ Two analyses of revascularization in patients with stable disease concluded that CABG resulted in lower fiveyear mortality, less angina and a reduced need for repeat revascularization compared with $\mathrm{PCl}$. (20,21) Analysis of a large non-randomized database in real-world practice showed that CABG offers a survival advantage to patients with disease involving two or more coronary arteries. ${ }^{(22)}$ At least part of the reason may be that CABG successfully treats both the lesion causing the angina and, unlike $\mathrm{PCl}$, provides an alternative conduit bypassing minor asymptomatic lesions, which are the determinants of future adverse events. ${ }^{(23)}$ These considerations lead one to question why patients with symptoms and anatomy known to benefit from CABG are still submitted to $\mathrm{PCl}{ }^{(13)}$ and to question why patients with minimal symptoms are treated by $\mathrm{PCl}$ before an adequate trial of medical therapy. An improvement in quality of life is often cited, but the available evidence suggests that $\mathrm{PCl}$ may result in worsening of measures of quality of life in patients who do not have bad symptoms. ${ }^{(24)}$

The popularity of $\mathrm{PCl}$ and its ready acceptance by patients with stable or minimal symptoms is surprising and presumably is based on a mistaken belief that it improves prognosis, is safe and free of complications. The latter is far from true. While technological advances and operator skill result in superb angiographic results in the majority of patients, there is a defined risk associated with $\mathrm{PCl}$. The published results from large real-world registries of usual practice indicate that the short-term risks are not negligible. ${ }^{25,26)}$ Patients and practitioners sometimes view PCl as a "holding" procedure, which delays $C A B G$ and there is a definite increase in the need for repeat revascularization, often by $\mathrm{CABG}$, in patients initially treated by $\mathrm{PCl}$. There is at least one observational study suggesting disturbingly that prior $\mathrm{PCl}$ may increase (double) in-hospital mortality after CABG. (27)

\section{DRUG-ELUTING STENTS}

Widespread optimism that the drug-eluting stents (DES) would make a significant impact on prognosis has been proven to be unfounded. The most recent four-year follow-up of comparisons of both CYPHER and TAXUS to bare metal stents show no difference in the incidence of the hard end-points of total mortality and myocardial infarction. (28) Those analyses were prompted by suggestions of excess mortality due to stent thrombosis in patients treated with DES in the BASKET trial. These results, controversial as they are and as yet unpublished, are a major cause for concern and should prompt re-evaluation of everyday practice. ${ }^{(29)}$

The necessity of prolonged dual antiplatelet therapy to prevent stent thrombosis is problematic at best in an older patient population who may require non-cardiac surgery in the weeks and months after $\mathrm{PCl}$. Compliance with expensive medication is difficult in our population and clopidogrel may be discontinued because of a patient's inability to afford it, or else at the whim of hospital or medical aid administrators. Inappropriate placement of a DES in a lesion causing minimal symptoms may convert an angiographic blemish into a fatal occlusion. Prior to valve replacement surgery, cardiologists spend a considerable amount of time determining whether patients are likely to be compliant with warfarin therapy, as this determines valve choice and long-term success. Similar careful screening is probably necessary before deciding on placement of a DES, but is difficult amid the pressures of an invasive procedure.

\section{CONCLUSION}

Simple lifestyle modification and drug therapy offer significant prognostic benefit to patients with stable angina. The advances in PCl technology offer dramatic symptomatic benefit to those whose symptoms are not tolerable, but this is not accompanied by any improvement in prognosis. In stable angina, the prognosis is such that it is hard to justify an invasive procedure that does not offer prognostic benefit, unless symptoms warrant it.

There are three concerns that can be raised about the emphasis placed on percutaneous revascularization in stable angina. The first relates to the diversion of resources. So much energy, enthusiasm and money is expended on a procedure that offers no prognostic benefit, that both in the public hospitals and in the private sector, individual patients' financial resources, medical aid resources and public hospital budgets may be exhausted to the extent that prognostically beneficial procedures, including CABG, may not be possible when they are truly needed. The second is a diversion of the patient's attention. Performance of $\mathrm{PCl}$ has become such a routine, sometimes almost outpatient procedure that patients do not appreciate the significance of their disease. They leave hospital thinking they are "cured" and return to unhealthy lifestyles in the mistaken belief that modern technology will rescue them again in future if it becomes necessary. The third is diversion of clinical attention. Any symptom vaguely suggestive of angina leads in some practitioners' hands to coronary angiography Coronary angiography will inevitably reveal coronary stenoses in some patients, particularly in an older population. Percutaneous intervention may well be performed on such incidentally discovered angiographic blemishes in the mistaken belief they are responsible for the presenting symptom. Delay in the diagnosis and treatment of the true cause of the symptoms may ensue. 
REFERENCES:

I. Kannel WB, Feinleib M. Natural history of angina pectoris in the Framingham study Prognosis and survival. Am J Cardiol 1972;29:154-63

2. Daly CA, De Stavola B, Fox KM, on behalf of the Euro Heart Survey Investigators. Predicting prognosis in stable angina - results from the Euro heart survey of stable angina: prospective observational study. BMJ 2006;332:262-5

3. Jabbour S, Young-Xu Y, Graboys TB et al. Long-term outcomes of optimized medical management of patients with stable coronary artery disease. Am J Cardiol 2004:93:294-9

4. Hueb W, Soares PR, Gersh B] et al. The medicine, angioplasty or surgery study(MASSII): A randomized, controlled clinical trial of three therapeutic strategies for multivessel coronary artery disease. J Am Coll Cardiol 2004;43:1743-51

5. Boden WE, O'Rourke RA, Teo $\mathrm{K}$ et al. Design and rationale of the clinical outcomes utilizing revascularization and aggressive drug evaluation (COURAGE) trial: Veteran Affairs cooperative studies program no. 424. Am Heart I 2006; I 51:1 I73-9

6. Teo KK, Ounpuu S, Hawken S et al. Tobacco use and risk of myocardial infarction in 52 countries in the INTERHEART study: a case-control study. Lancet 2006;368:647-58

7. Bartecchi C, Alsever RN, Nevin-Woods $C$ et al. Reduction in the incidence of acute myocardial infarction associated with a citywide smoking ordinance. Circulation 2006; 1 1 4:1490-6

8. Barnoya J, Glantz SA. Cardiovascular effects of secondhand smoke. Nearly as large as smoking. Circulation 2005; 1 1 1:2684-98

9. Thompson PD. Exercise prescription and proscription for patients with coronary artery disease. Circulation 2005; 1 12:2354-63

10. Hambrecht R, Walther C, Mobius-Winkler S et al. Percutaneous coronary angioplasty compared with exercise training in patients with stable coronary artery disease: a randomized trial. Circulation 2004; 109:137|-8

1।. lestra JA, Kromhout D, van der Schouw YT et al. Effect size estimates of lifestyle and dietary changes on all-cause mortality in coronary artery disease patient: A systematic review. Circulation 2005; I 12:924-34

12. Patrano C, Garcia Rodriguez LA, Landolfi R, Baigent C. Low-dose aspirin for the prevention of atherothrombosis. N Engl J Med 2005;353:2378-83

13. Opie LH, Commerford PJ, Gersh BJ. Controversies in stable coronary disease. Lancet 2006;367:69-78

14. HOPE / HOPE-TOO Study Investigators. Long-term effects of ramipril on cardiovascular events and on diabetes. Results of the HOPE study extension. Circulation 2005; | | 2:1339-46

15. Al-Mallah MH,Tleyjeh IM, Abdel-LatifAA, WeaverWD. Angiotensin-converting enzyme inhibitors in coronary artery disease and preserved systolic function. J Am Coll Cardiol 2006:47:1576-83

16. Heidenreich PA, McDonald KM, Hastie T et al. Meta-analysis of trials comparing betablockers, calcium antagonists and nitrates for stable angina. JAMA 2004:292:2227-36

17. Gislason $\mathrm{GH}$, Jacobsen S, Rasmussen JN et al. Risk of death or reinfarction associated with the use of selective cycloxygenase- 2 inhibitors and nonselective nonsteroidal antiinflammatory drugs after acute myocardial infarction. Circulation 2006; | 1 3:2906- 13

18. Yusuf S, Zucker D, Peduzzi P et al. Effect of coronary bypass graft surgery on survival: overview of 10-year results from randomized trials by the Coronary Artery Bypass Graft Surgery Trialists Collaboration. Lancet 1994;344:563-70

19. Katritsis DG, loannidis JPA. Percutaneous coronary intervention versus conservative therapy in nonacute coronary artery disease. Circulation 2005; 1 I 1:2906-12

20. Hoffman SN, TenBrook JA, Wolf MP, Pauker SG, Salem DN, Wong JB. A meta-analysis of randomized controlled trials comparing coronary bypass graft with percutaneous transluminal coronary angioplasty: one- to eight-year outcomes. J Am Coll Cardiol 2003;41:1293-304

21. Rihal C, Raco D, Gersh B], Yusuf S. Indications for coronary bypass surgery and percutaneous coronary intervention in chronic stable angina. Circulation 2003; 108:2439-45

22. Hannan EL, Racz MJ,Walford G et al. Long-term outcomes of coronary-artery bypass grafting versus stent implantation. N Engl J Med 2005;352:21 74-83

23. Gersh B]. Frye RI. Methods of coronary revascularization - things may not be as they seem. N Engl J Med 2005;352:2235-37

24. Spertus JA, Salisbury AC, Jones PG et al. Predictors of quality of life after percutaneous coronary interventions. Circulation 2004; I 10:3789-94

25. Burton KR, Slack R, Oldroyd KG et al. Hospital volume of throughput and periprocedural and medium-term adverse events after percutaneous coronary intervention; retrospective cohort study of all 17,417 procedures undertaken in Scotland, 19972003. Heart; 2006:1667-1672

26. Wu C, Hannan EL, Walford G et al. A risk score to predict in-hospital mortality for percutaneous coronary interventions. I Am Coll Cardiol 2006:47:654-60

27. Hassan A, Buth K, Baskett RJF et al. The association between prior percutaneous coronary intervention and short-term outcomes after coronary artery bypass grafting. Am Heart J 2005; 150: 1026-31

28. http://www.the heart.org Accessed 25 October 2006

29. Shuchman M. Trading restenosis for thrombosis? New questions about drug-eluting stents. N Engl J Med 2006;355:1949-52 